\title{
Duodenal duplication cyst causing acute recurrent pancreatitis, managed curatively by endoscopic
}

\section{marsupialization}
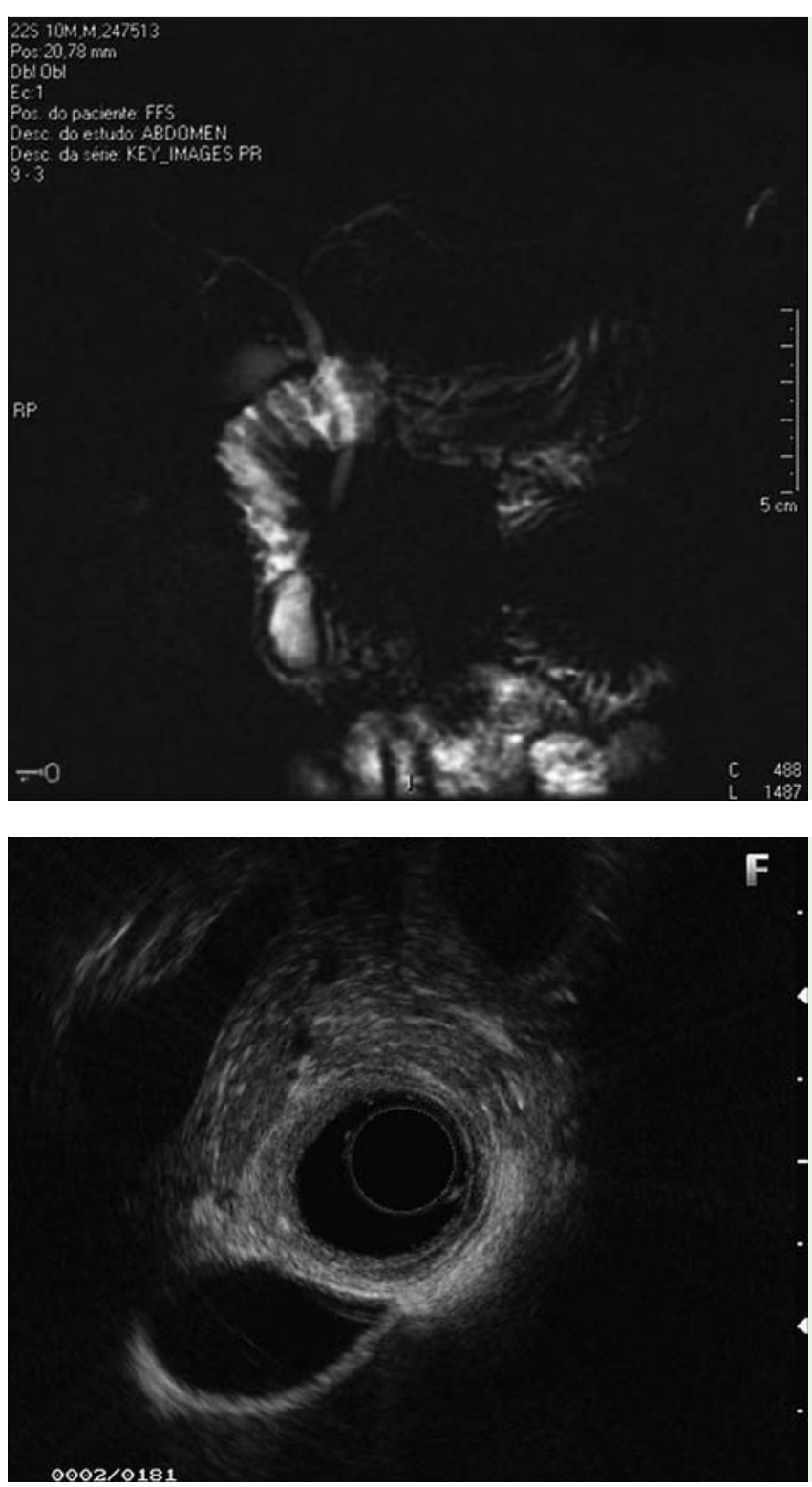

Duodenal duplication cyst (DDC) is a rare congenital anomaly that typically presents with symptoms during childhood [1]. Acute pancreatitis and biliary obstruction have rarely been reported in adults $[2,3]$. Two modalities of treatment have been described for DDCs: surgical $[4,5]$ and endoscopic, by means of cyst marsupialization [1]. The rationale behind cyst marsupialization is to establish communication between the cyst cavity and the duodenal lumen so that the cystic contents can drain continuously into the duodenum [1].
Fig. 1 Magnetic endoscopic retrograde cholangiopancreatography (MRCP) in a 22-year-old man with acute recurrent pancreatitis showing a regular cyst in the duodenal lumen, $23 \times 17 \mathrm{~mm}$ in size, close to the major duodenal papilla.

Fig. 3 Endoscopic ultrasound showing a submucosal anechoic consistent with a duodenal duplication cyst.

We report a case of a 22-year-old man with a history of six episodes of acute recurrent pancreatitis (ARP) of unknown origin. Some of the episodes were severe and required hospitalization for 6-49 days. Magnetic retrograde cholangiopancreatography (MRCP) showed a regular cyst in the duodenal lumen, measuring $23 \times 17 \mathrm{~mm}$, close to the major duodenal papilla ( Fig.1). The lesion was erroneously diagnosed as a type III choledochal cyst and patient was referred to our institution for endoscopic sphincter-

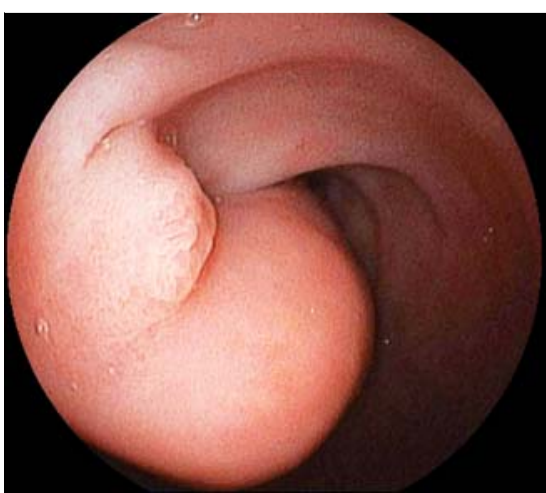

Fig. 2 Endoscopic view of the duodenal duplication cyst. Note that the cyst is situated distal to the papilla.

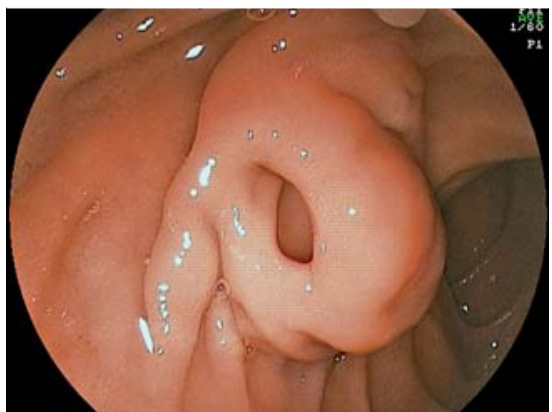

Fig. 4 Endoscopic view 2 years after endoscopic marsupialization showing a collapsed cyst and wide communication with the duodenal lumen. The papilla can be seen at the proximal margin of the cyst.

otomy. We decided to perform duodenoscopy ( Fig.2) and radial endoscopic ultrasound ( Fig.3), which showed a bulging duodenal anechoic cyst with distinct walls, situated adjacent to the papilla at its anal margin. The cyst was covered by normal mucosa and measured $2.28 \times 1.39 \mathrm{~cm}$, with an internal volume estimated at $2.6 \mathrm{~mL}$. Endoscopic retrograde cholangiopancreatography (ERCP) revealed normal findings, with no communication between the cyst and the pancreatic or common bile duct. A diagnosis of DDC was made and endoscopic treatment by means of cyst marsupialization was proposed.

The procedure involved wide opening of the cyst wall with a needle-knife (Needle-knife Papillotome, Cook Medical, Bloomington, Indiana, USA), followed by 
snare resection of the margins with a rotatable hexagonal snare (Boston Scientific, Natick, Massachusetts, USA) ( Video 1 ). The patient had an uneventful recovery and was discharged after 6 hours of observation. Histological assessment of the specimen confirmed the diagnosis of DDC. The patient has been under clinical and endoscopic follow-up for the past 4 years and remains asymptomatic, with no further episodes of pancreatitis. The 2-year follow-up endoscopy revealed effective communication between the cyst and the duodenal lumen through a wide opening in the cyst margin ( Fig.4).

The present case highlights the need to consider DDC in the differential diagnosis of ARP in young patients, and the lesion must be carefully assessed with duodenoscopy and endoscopic ultrasound in order to distinguish it from a choledochocele. This case also demonstrates that cyst

\section{Video 1}

Opening of the cyst wall with a needle-knife, followed by snare resection of the margins with a rotatable hexagonal snare. marsupialization is a minimally invasive treatment modality that can provide an adequate specimen for diagnostic confirmation and can be carried out with curative intent in the short and in the long term.

\section{Endoscopy_UCTN_Code_CCL_1AF_2AD}

Competing interests: None

\section{Arantes, S. R. B. Nery, S. V. Starling, W. Albuquerque, L. R. Alberti}

Endoscopy Unit, Alfa Institute of Gastroenterology, Hospital of Clinics of the Federal University of Minas Gerais, Belo Horizonte, Brazil

\section{References}

1 Antaki F, Tringali A, Deprez P et al. A case series of symptomatic intraluminal duodenal duplication cysts: presentation, endoscopic therapy, and long-term outcome. Gastrointest Endosc 2008; 67: 163-168

2 Stelling T, von Rooij WJ, Tio TL et al. Pancreatitis associated with congenital duodenal duplication cyst in an adult. Endoscopy 1987; 19: $171-173$
3 Guarise A, Faccioli N, Ferrari $M$ et al. Duodenal duplication cyst causing severe pancreatitis: imaging findings and pathological correlation. World J Gastroenterol 2006; 12: $1630-1633$

4 Ackerman NB. Duodenal duplication cysts: diagnosis and operative management. Surgery $1974 ; 76$ : $330-333$

5 Merrot T, Anastasescu R, Pankevych $T$ et al. Duodenal duplications. Clinical characteristics, embryological hypotheses, histological findings, treatment. Eur J Pediatr Surg 2006; 16: $18-23$

\section{Bibliography}

Dol http://dx.doi.org/

10.1055/s-0031-1291674

Endoscopy 2012; 44: E117-E118

(C) Georg Thieme Verlag KG

Stuttgart · New York

ISSN 0013-726X

\section{Corresponding author}

\section{Dr V. Arantes}

Rua Florália 18

Apt. 1201

Anchieta

Belo Horizonte 30310-690

Brazil

arantesvitor@hotmail.com

arantesvitor@ufmg.br 